\title{
EVALUATION OF INVASIVE RETROFITTING INTERVENTIONS ON AN UNREINFORCED MASONRY HERIRAGE BUILDING
}

\author{
A.SCUPIN ${ }^{1 *}$, R.VĂCĂREANU ${ }^{1}$ AND F.PAVEL ${ }^{1}$ \\ ${ }^{1}$ Seismic Risk Assessment Research Center (CCERS) \\ Technical University of Civil Engineering Bucharest \\ Bd. Lacul Tei no. 122-124, Bucharest 020396, Romania \\ e-mail: anda.scupin@yahoo.com,www.ccerc.utcb.ro
}

Keywords: Historical Structure, Geology Museum, Unreinforced Masonry, Invasive retrofitting

\begin{abstract}
The present study case highlights the importance of considering local failures for irregular unreinforced masonry buildings, by means of nonlinear seismic analyses. Simplified seismic assessments based on equivalent frame method were used in order to capture the structural behavior of the National Geological Museum from Bucharest in its initial form and also the current structural layout.

The retrofitting works realized in the 1982 were focused on strengthening the transversal masonry walls and on creating horizontal diaphragms to improve the "box behavior" of the building subjected to lateral forces. Retrofitting of unreinforced masonry walls by reinforced concrete jacketing and the replacement of flexible floors by reinforced concrete slabs were previously considered to be effective only though post-earthquake visual inspections of the strengthened elements. The efficiency of past interventions is studied in the present paper through comparisons between the two models in terms of damage patterns, global behavior and also performance levels established function of maximum relative displacements.
\end{abstract}

\section{INTRODUCTION}

\subsection{Brief history}

The building hosting nowadays the National Geological Museum was built at the beginning of the 20th century, in between 1904-1906 by architect Ion Ștefănescu. Located in Bucharest, it was initially designed as headquarters of the National Geological Institute and transformed in museum in 1975. The building is listed on the cultural heritage list as having significant importance in the local context.

\subsection{Structural layout}

The museum's complex is formed by two wings with different heights and layouts, even 
though not separated through seismic joints. The main wing has a U-shape layout composed of a semi-basement of $4.40 \mathrm{~m}$ height, a ground floor of $6.80 \mathrm{~m}$ and a first floor of $5.60 \mathrm{~m}$. The secondary wing is located on the backside of the building and hosts the main staircase shown in Figure 1, as well as the exhibition hall with more than $12 \mathrm{~m}$ clear height. The connection between the two wings is done only through the circular walls of the hallway and though the stair landings. The lack of appropriate separation joints between the two wings with different stiffnesses represents one of the major structural deficiencies.
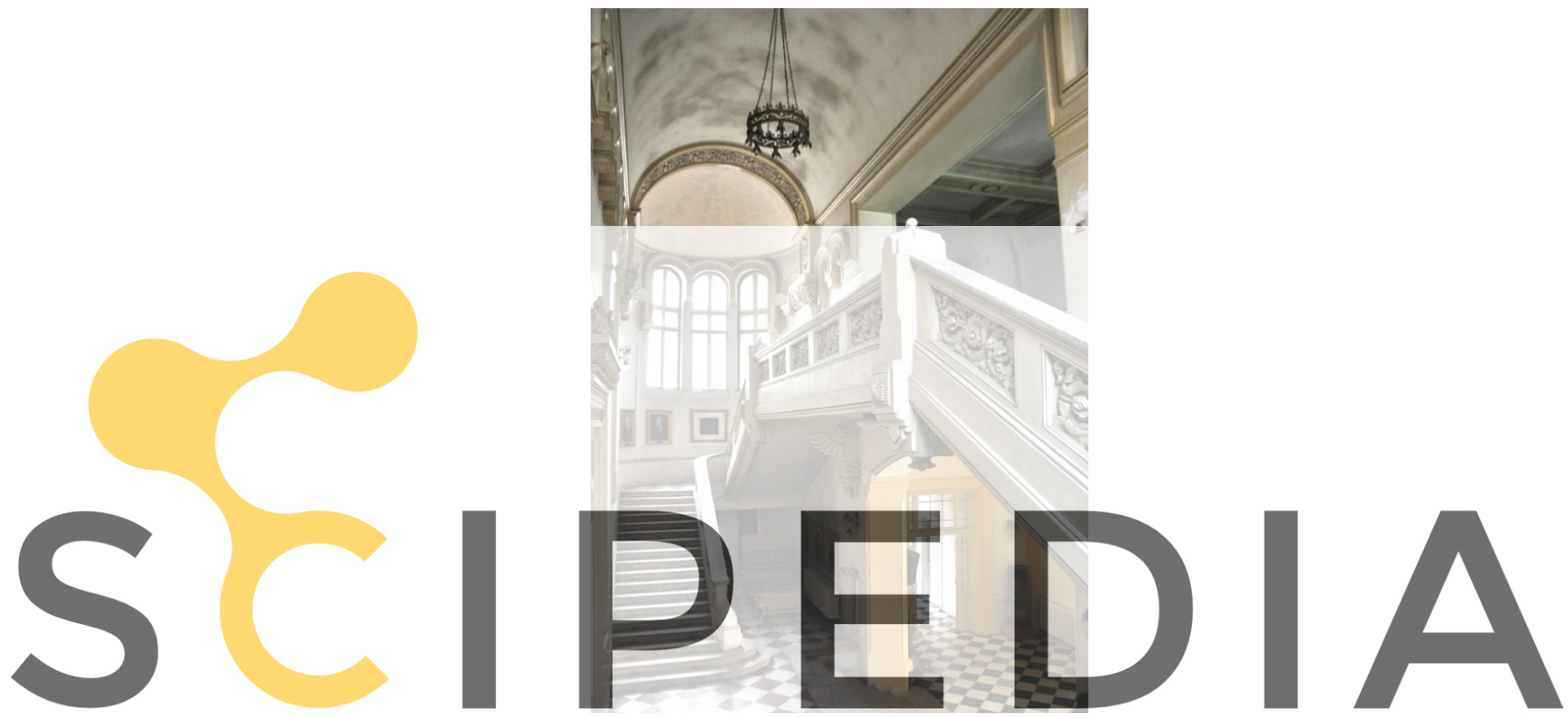

Figure 1: Main stairway linking the principal wing and the exhibition hall

Register for free at https//www.scipedia.com to download the version without the watermark Both exterior and interior walls are made of clay brick masonry and lime mortar with variable thicknesses along the height of the building. Reductions of the walls' thickness range from $25 \%$ up to $55 \%$, thus creating major differences of wall's areas for each floor. In most of the cases, the masonry walls are continuous along the entire height, following the proportions of structural elements specific for the time of construction. Even though increased story height favors the creation of high horizontal coupling elements above openings of about $2 \mathrm{~m}$, the openings of the main facades do not follow this layout. The uneven placement of windows on the principal façade, as well as the reduced height of the spandrels from the first floor creates considerable stiffness differences in between exterior and interior walls. Similarly, the openings on the walls of the back façade present an irregular alignment. These deficiencies led most probably to the creation of buttresses to support the walls of the secondary wing, as it can be observed in Figure 2Figure $z$ 


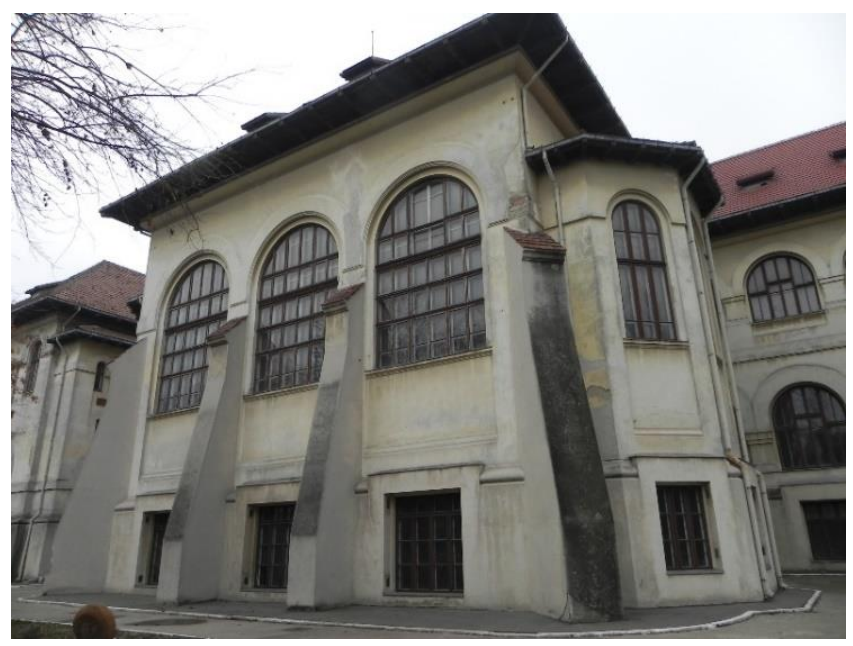

Figure 2: View of the back facade of the National Geological Museum (secondary wing)

Apart from uneven placement of openings, the front façade also has an important discontinuity at the upper level of the balcony. The area situated above the main entrance is composed of columns and arches that support the upper level of the attic, as pictured in Figure 3.

Initially, the building had flexible floors made of metallic profiles and vaults for the partial basement and made of metallic profiles or wooden beams for the upper floors. The roof structure is made of wooden frames, having a particularly increased height reaching about 10
. Hence, several high walls from the attic level present inappropriate anchorages in orde to support horizontal actions. The vault covering the exhibition hall is made of reinforced concrete, while the vault of the stairways is made of a light weight material, namely reinforced mortar. The vaulted structure of the secondary wing marks one of the lirst practiees for using reinforced concrete in Romania.

Register for free at https//www.scipedia.com to download the version without the watermark

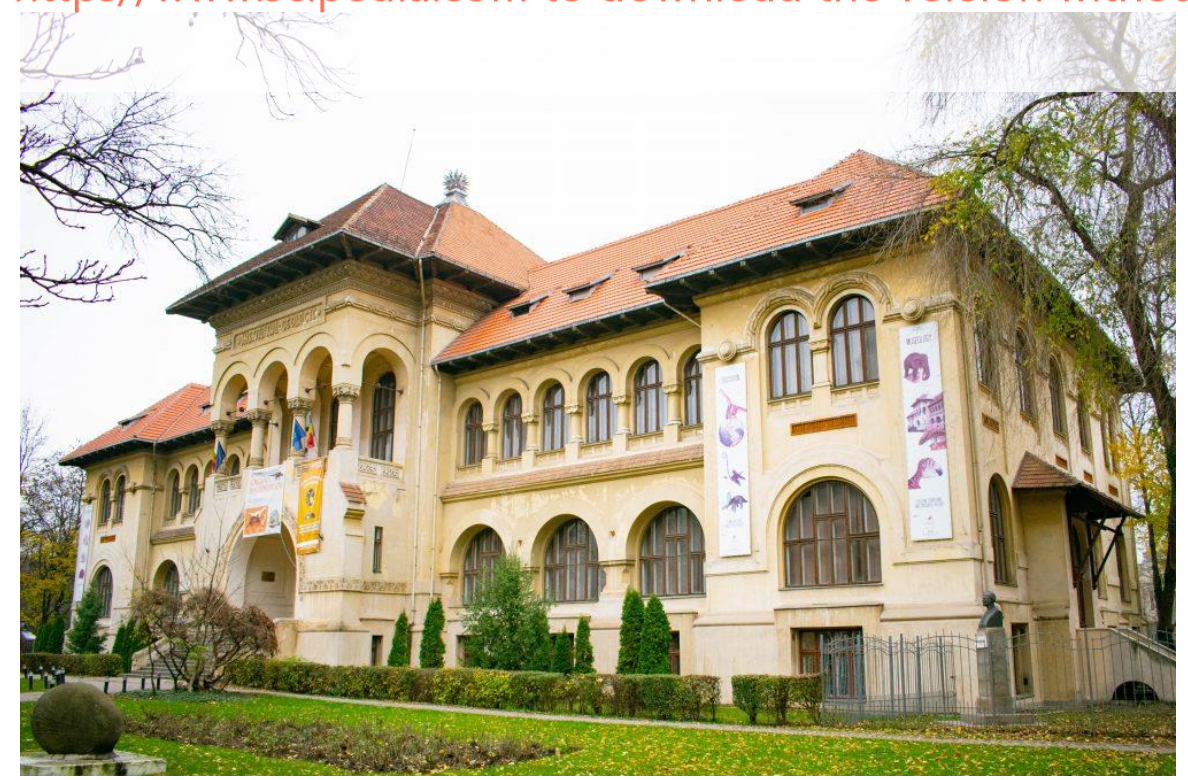

Figure 3: Main facade of the National Geological Museum 


\section{POST EARTHQUAKE STRUCTURAL BEHAVIOUR}

Some of the main structural deficiencies noted in previous seismic assessments refer to the aspects previously presented with respect to the openings positioning and proportions, masonry walls' thickness reduction along height, lack of separation joints between the two wings and also improper connections of the structural walls at the attic level.

The museum was strongly affected by strong earthquakes which happened during the 20th century in Romania (1940, 1977, 1986 and 1990) and also by the World War II bombing in Bucharest (1944). Severe local damages were caused in the 1944, as it can be seen in Figure 4. According to past damage assessments [1], the earthquake from 1940 caused "significant degradations of the structural walls" that were not repaired not strengthened. Therefore, the strong ground motion from 1977 acted on a structure already damaged. Some of the damages observed after this seismic event range from cracking and debonding up to local collapse of nonstructural parts. The failure mechanisms consisted mainly in diagonal cracking (step-wise) and bending failure in the case of slender piers, such as the ones from the main façade of the building. The global behavior was governed by "walls with small openings" due to the increased width of spandrels, which remained undamaged. The most affected area was the portico of the front façade, due to uneven layout of transversal walls from the interior, with respect to the marginal walls of the balcony. This led to partial detachments of the portico from the main façade. More damages to the curves nonstructural walls improperly caused its destruction.
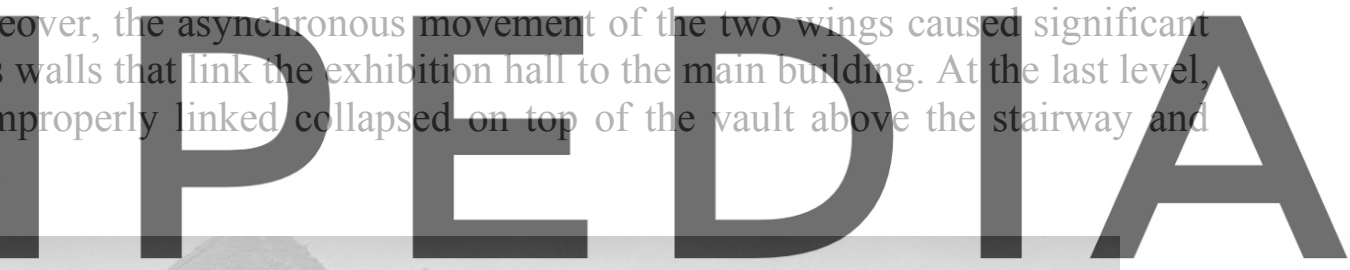

Register for free at https//www.scipedia.com to download the version without the watermark

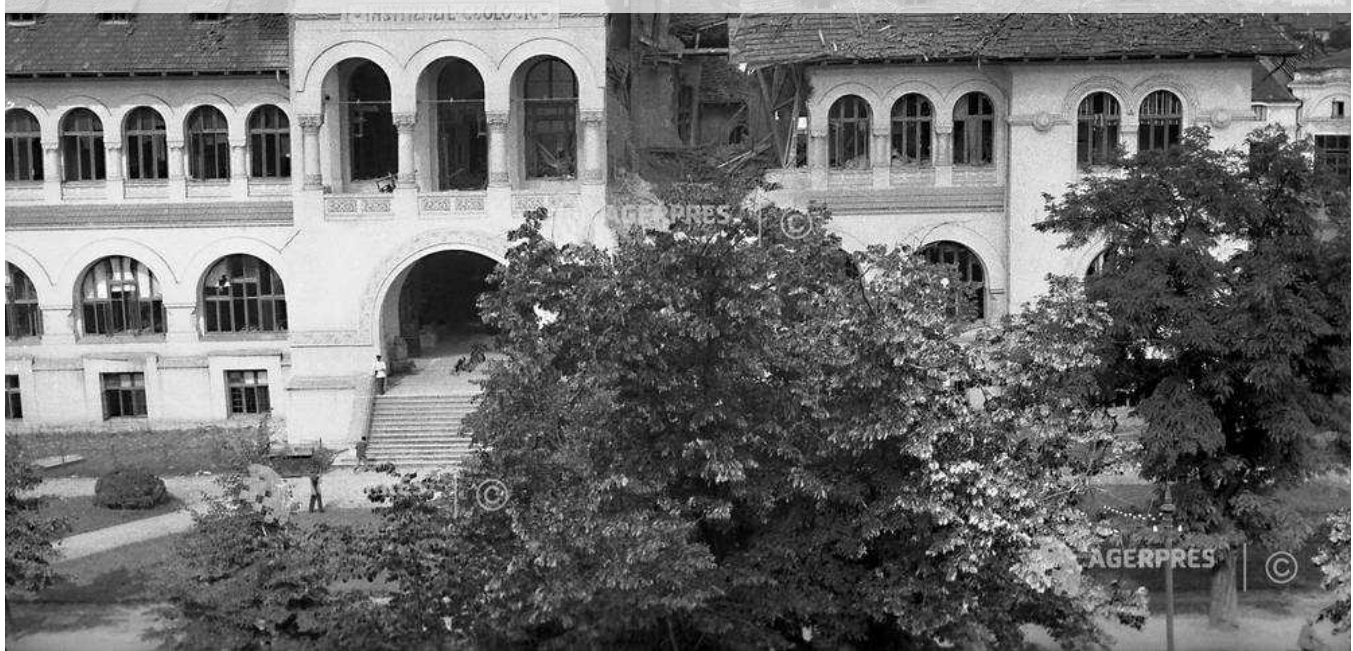

Figure 4: The National Geological Institute after the bombing from 1944, 23rd August (Agerpres Archive - foto no. 7646690 ) 
In order to repair and strengthen the building, retrofitting works started in 1982. The main goals were to replace the flexible flooring with reinforced concrete slabs, to repair cracks by means of grout injections and also strengthen masonry walls using reinforcement bars or welded meshes. Metallic tie-rods were added in the most vulnerable parts, namely the portico and other partially collapsed parts. Apart from these local interventions, several transversal interior walls of the main wing were jacketed with reinforced concrete $(10 \mathrm{~cm}$ thick layers $)$ or reinforced mortar (4 cm thick layers).

The following seismic events from 1986 and 1990 did not cause any damages in the retrofitted areas and even improved the "box behavior" of the building subjected to lateral forces. Even though the global behavior was observed to be improved, supplementary retrofitting works were recommended to be undertaken in order to reach the safety standards for existing buildings, according to current regulations.

\section{NUMERICAL MODELS}

Starting from the damage assessment previously presented and also based on previous research related to material behavior of clay bricks used in the beginning of the 20th century, a numerical model of the buildings was calibrated. The software used was Tremuri [2] due to its ability to model masonry walls as assemblages of deformable macro-elements (piers and spandrels) linked by rigid nodes. The layout of the structure was slightly simplified in order to

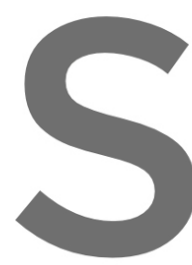
adapt to the modeling approximated by orthog layout of the building modelled i
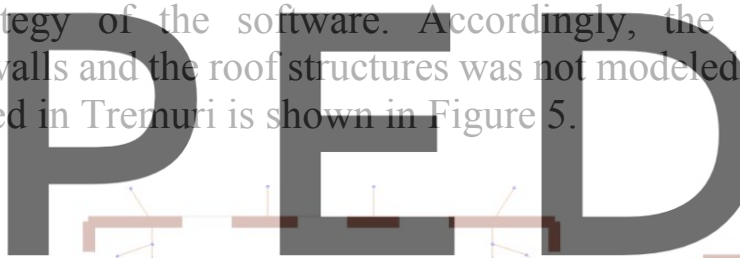

(i)

Register for free at https'/Www.scipedia.com to download the version without the watermark

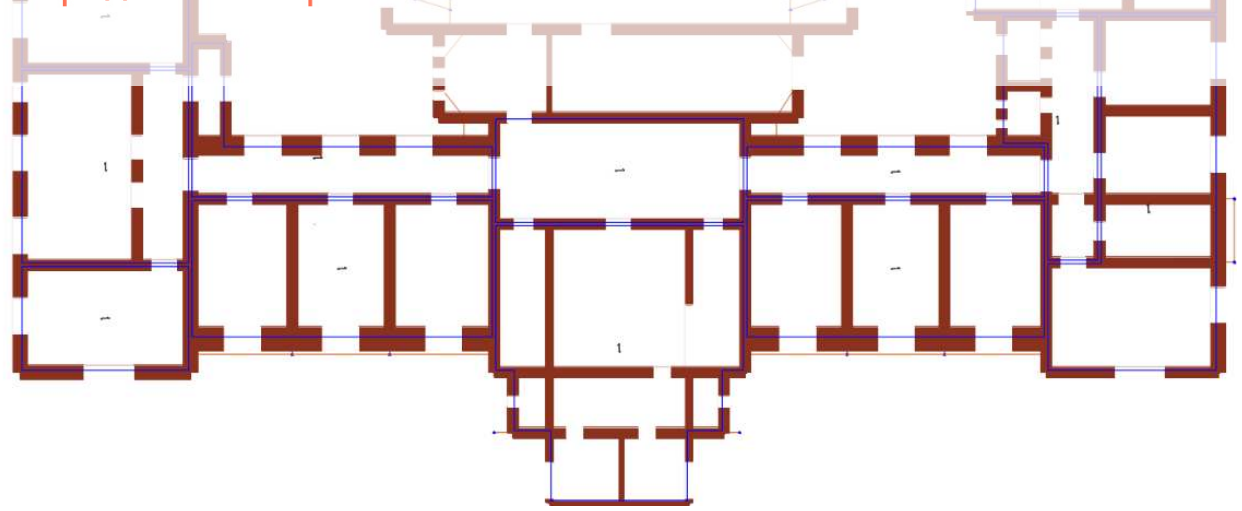

Figure 5: Structural layout of the building (Tremuri)

\section{COMPARATIVE RESULTS OF THE STATIC NONLINEAR ANALYSES}

In order to analyze the change in behavior generated by the retrofitting interventions done in the 80s', two numerical models were compared (initial structure and retrofitted structure) through Pushover analyses, damage patters and maximum displacements. The changes 
implemented for the retrofitted model consist in improved material characteristics for the masonry walls retrofitted by RC jacketing, according to the sketch presented in Figure 6 and also modelling the slabs as rigid diaphragms.
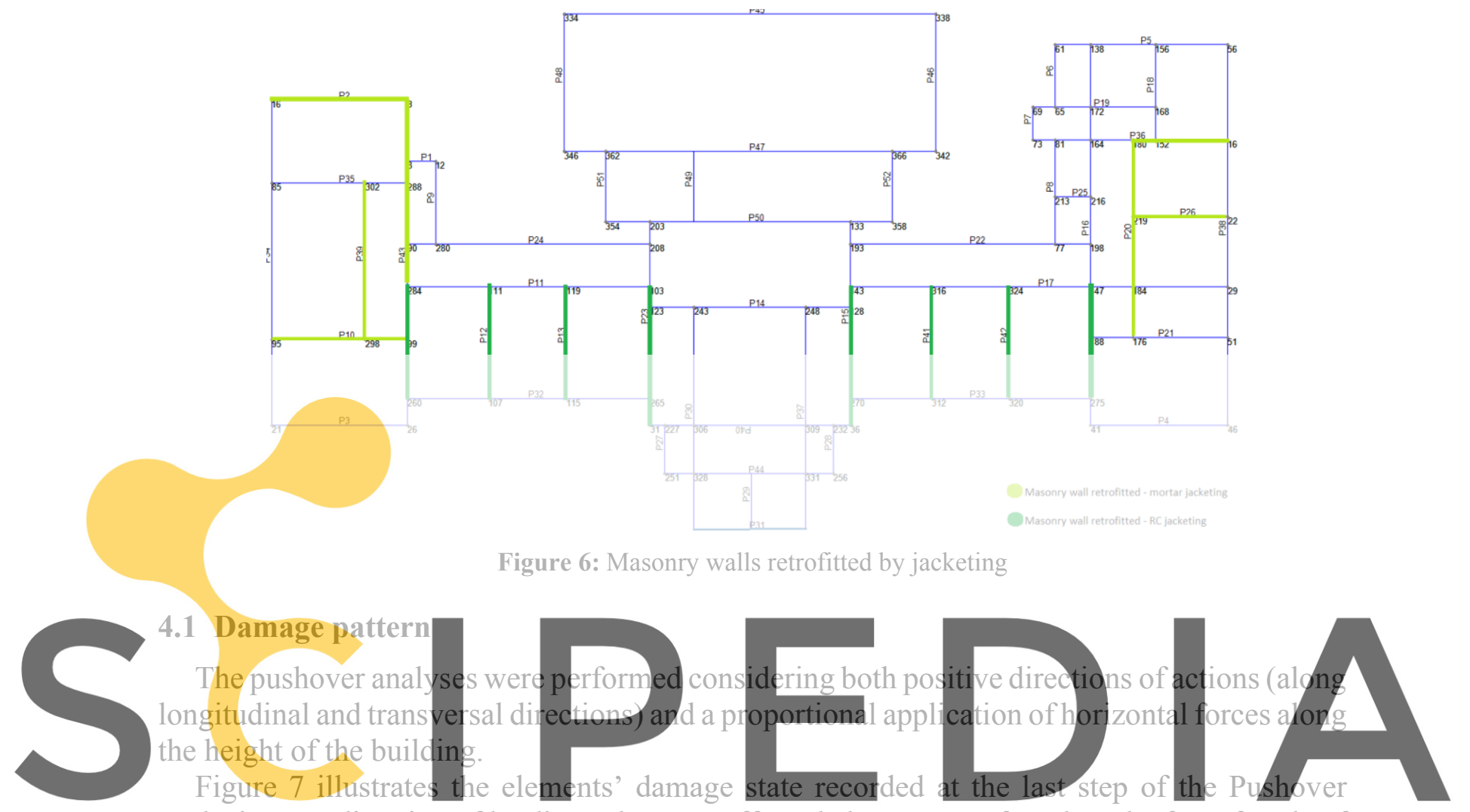

analysis on X direction of loading. The most affected elements are found on the front façade of

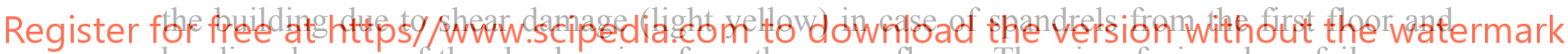
bending damage of the slender piers from the upper floors. The piers facing shear failure are colored in orange and they correspond to the level where changes in openings position appear (ground floor - first floor). Comparing these damages stages with the ones recorded on the retrofitted model on the left, it can be observed that bending failure (red colored elements) appear on top of the back-façade walls. The lack of proper separation between the two wings was not solved through the retrofitting interventions carried out in 1982-1984. Moreover, since jacketing measures were taken for walls of the main wing, even greater difference in terms of stiffness tend to appear in between the two building parts.

\subsection{Pushover curves}

Pushover curves were obtained for both static and uniform loading patterns are presented in Figure 8 in order to highlight the differences between the initial and the retrofitted models. From the point of view of stiffness of the models, it can be observed that the initial model with flexible floors has different results for both loading directions. In the case of the retrofitted model, there are no longer present such variations in terms of stiffness, due to a more unitary behavior along the orthogonal directions, as desired for the structures with rigid diaphragms. 

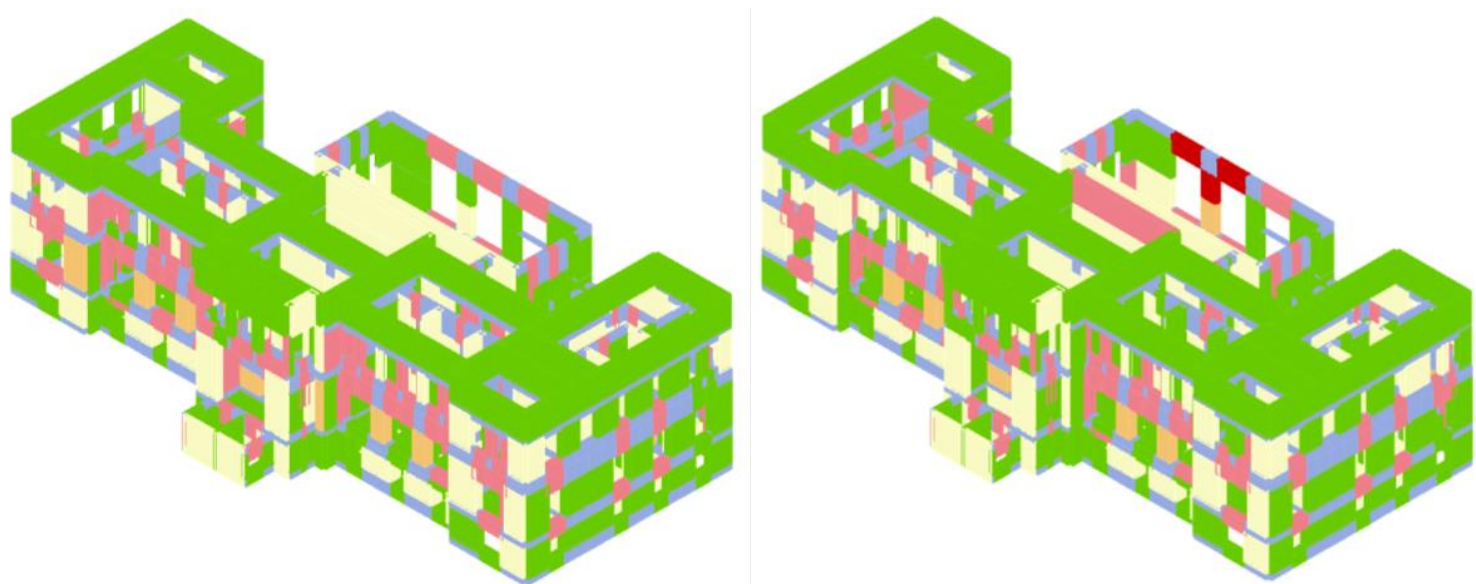

Figure 7: Comparative results for the Static Pushover: initial structure (left) and retrofitted structure (right) longitudinal loading direction (X)

The improvements observed in terms of maximum horizonal force are significant on $\mathrm{Y}$ direction, where both Pushover loading patterns reach about $80 \%$ increase in strength. Taking into account that most of the interventions were concentrated on transversal walls, almost no changes are recorded on the results from longitudinal loading direction, when comparing the initial structure with the retrofitted one.

Since the retrofitting works were designed to increase the strength, no improvements are

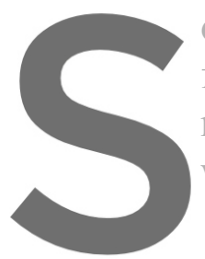
observed in terms of increased displace from the nonlinear static model, especially in the works on masonry walls were concentrated.
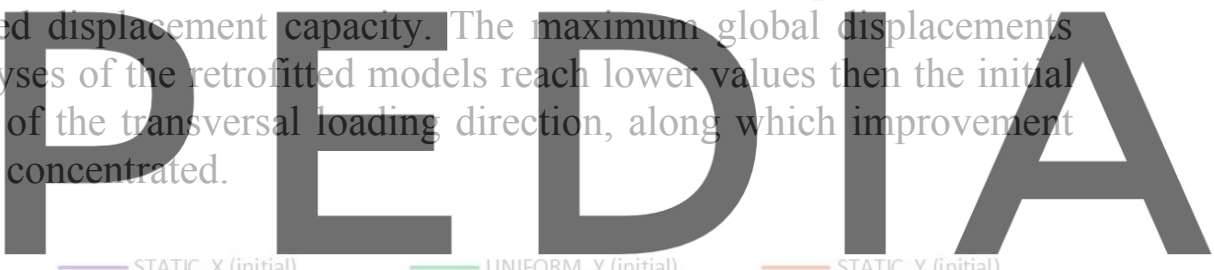

Register for free at https//www.scipedia.com to download the version without the watermark

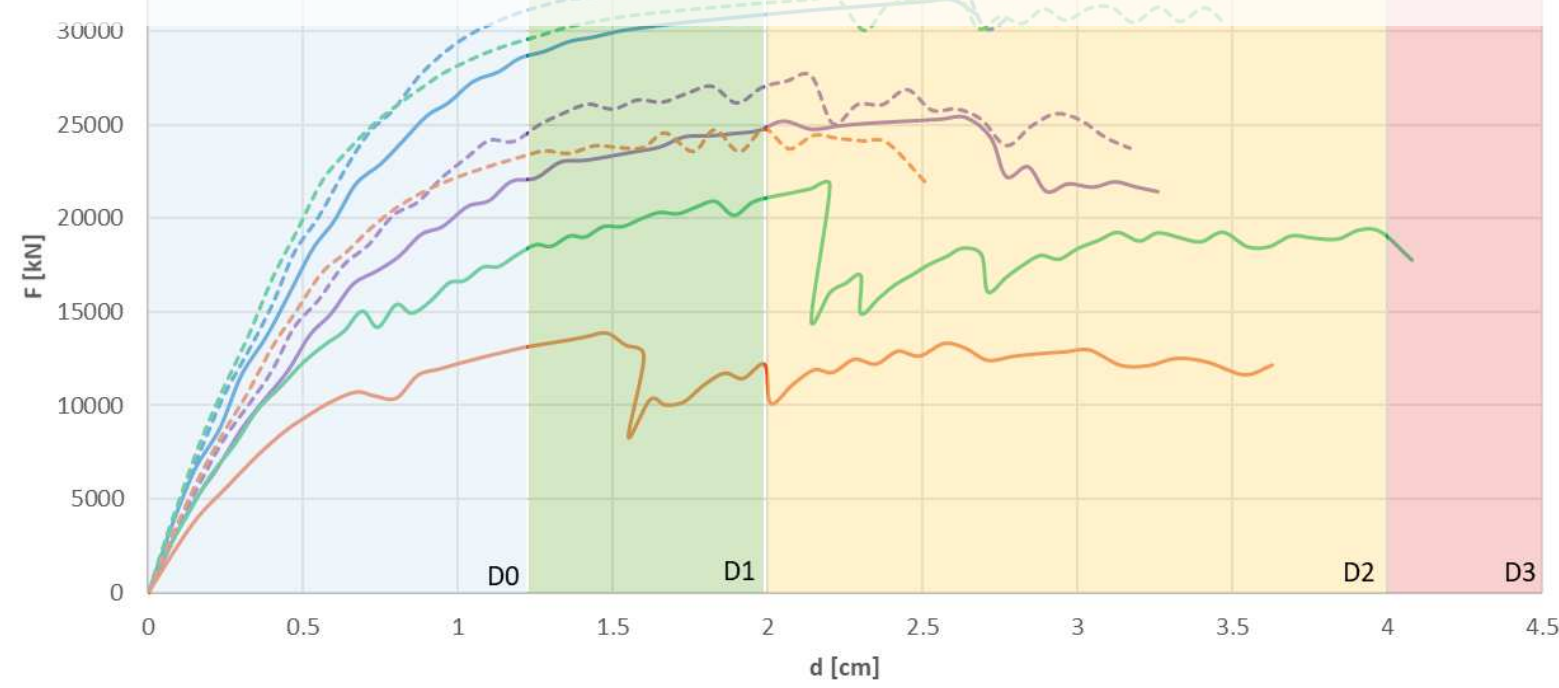

Figure 8: Pushover curves comparison 


\subsection{Global and relative displacements}

In case of unreinforced masonry buildings with variable wall thicknesses, irregular damage distribution is frequently observed in post-damage seismic assessments [3]. As in the case herein presented, severe damages tend to concentrated at floors where changes of layout or wall thickness appear. Since global values of ultimate displacements may not reflect the maximum displacement values reached in areas with local failures, an additional analysis was done in order to evaluate relative displacements at the floor and at the wall level.

Previous literature studies highlight the significant differences between global and local ultimate displacements in case of masonry structures, proposing also threshold limits for each of these [3]. Typical drift values for unreinforced masonry walls presented in ASCE [4], as well as global drift limits proposed in literature [5] were summarized in Table 1 and further compared with the relative displacements obtained for the National Geological Museum. The global drift limits expressed function of the height of the building $(19.85 \mathrm{~m})$ are overlapped with the global Pushover curves in Figure 8. It can be observed that only for one of the analyses the collapse prevention limit is reached, namely for the initial model, uniform loading pattern in transversal direction, while all the other ultimate displacements indicate the life safety performance level.

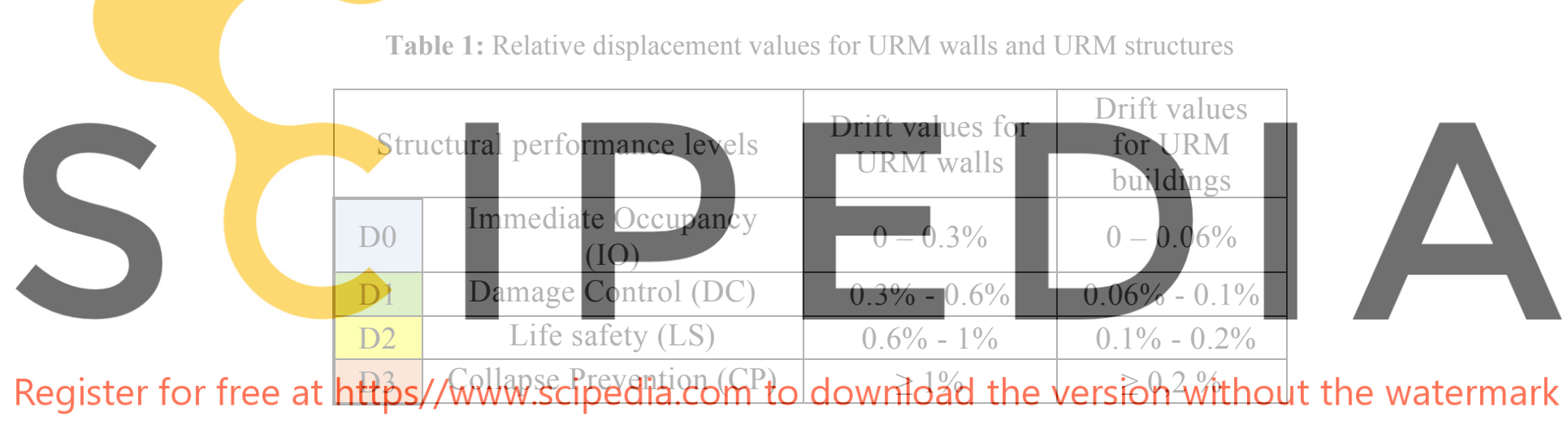

Taking into account that the global nonlinear analyses do not reach target displacements estimated based on equivalent single degree of freedom systems, it can be concluded that local failures occur before the global collapse of the structure. In order to check if the numerical models were able to capture the damage areas noted in the post-earthquake assessments, the relative floor and walls displacements, as well as the damage state of the elements was analyzed.

The highest relative displacements resulted from the Static Pushover case on the initial model appear at the walls from the ground floor level in case of longitudinal loading direction and on the first level for the transversal loading direction. For X direction, almost $30 \%$ of the masonry walls form the ground floor overpass the drift limit corresponding to damage control, with 2- $3 \mathrm{~cm}$ displacement. In case of Y loading direction, more than $20 \%$ of the walls reach the life safety stage with relative displacements higher than $3.6 \mathrm{~cm}$. The highest relative displacements are recorded on one of the portico's sides (wall 28) and also the adjacent interior wall no. 15, marked with red on Figure 9. Their displacements correspond to the collapse prevention performance limit, according to the drift proposed as reference by ASCE [4]. The highest relative displacement recorded for the longitudinal direction is also highlighted in green for the wall no. 44 in Figure 9. 


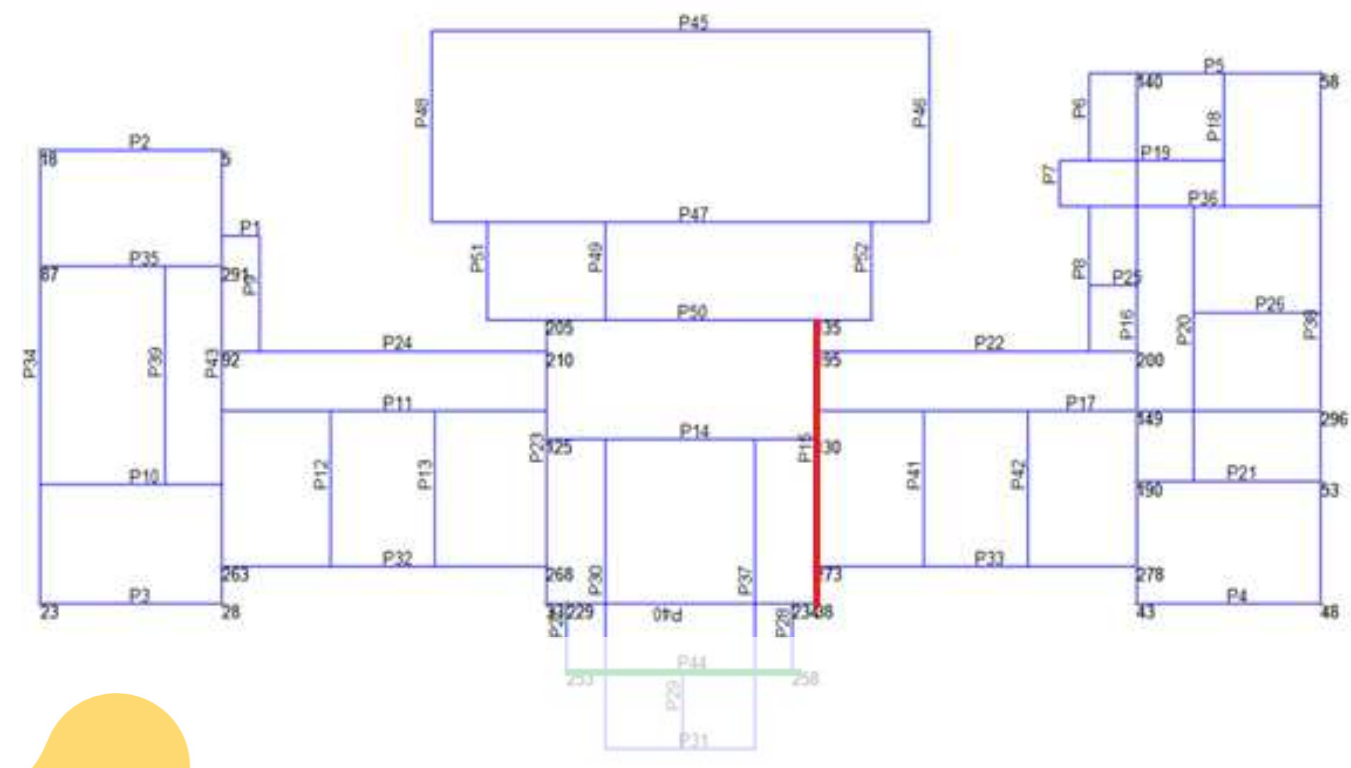

Figure 9: Damage stage color code for all the walls with highest relative displacements

These results are in good accordance with the information regarding the damage assessment, showcasing once again the local vulnerabilities caused by the portico, the openings layout of the main façade as well as the misalignment of transversal interior walls. For wall no. 44 and

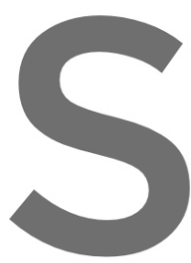
no. 15 , detailed results

displacements recorded elements. Since wall $n$ between results of the in For wall no. 44, plac
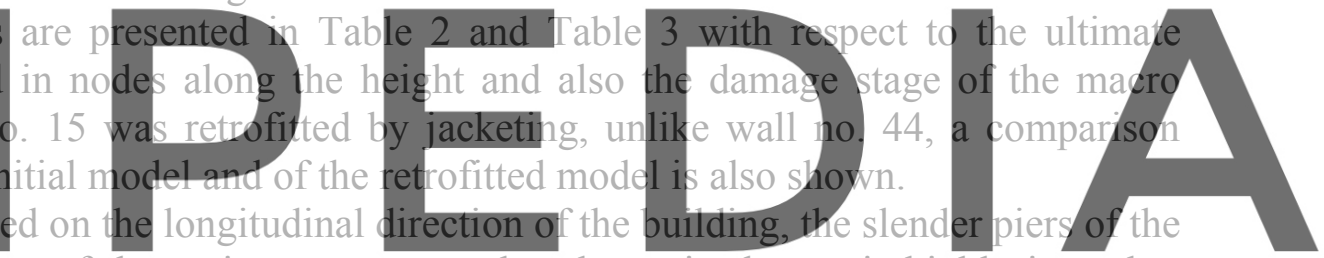

portico are placed on top of the main entrance, so that the entire layout is highly irregular.

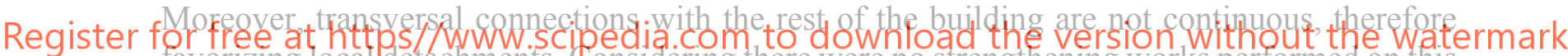
favorizing localdetachments. Considering there were no strengthening works performed on this façade wall, nor other significant works on the longitudinal direction, there are no major changes observed for the retrofitted model.

In case of wall no.15, the highest drift appears at the first level, where important stiffness differences appear along the height of the wall due to placement of openings. After the jacketing of the wall with $20 \mathrm{~cm}$ of RC on both sides, the damage distribution along the macro-elements is completely changed, as it can be observed in the retrofitted model from Table 3 . Bending of the pier from the first floor is avoided and the relative displacements decrease below the Damage Control drift limit.

When comparing the initial model with the retrofitted one, significant improvements are observed for the transversal direction. Considering the numerous constrained specific for heritage buildings, jacketing works were only possible in few places, mostly on the transversal direction. These types of traditional reinforcements applied for unreinforced masonry are considered to be similar to the addition of new reinforced concrete walls [6] and were extensively used at the end of the $20^{\text {th }}$ century and combined with less invasive interventions [7]. Adding layers of reinforced concrete on masonry walls increases strength, anyhow restraining the deformation capacity of the structural element. Lateral cyclic laboratory tests 
performed in Skopje [8] concluded that jacketing of URM walls subjected to high compressive forces decreases their displacement capacity. Therefore, the efficiency of this retrofitting method depends on their proportions, being more adequate for walls with an aspect ratio between height and length of about 0.7 , rather than slender walls.

Table 2: Relative displacements of wall no. 44 (longitudinal loading direction)

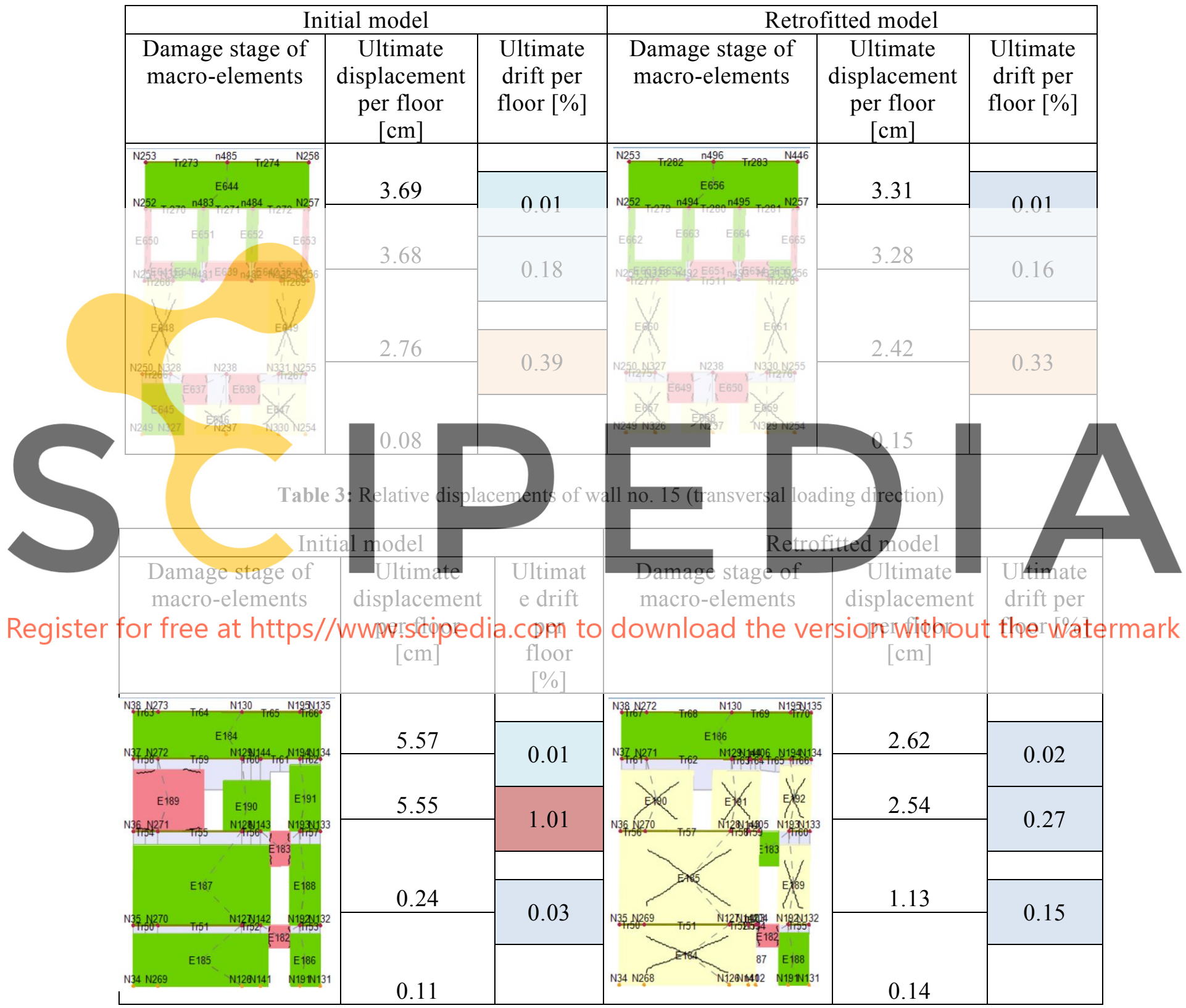




\section{CONCLUSIONS}

The numerical models proposed for the National Geological Museum were validated by comparison with the post-earthquake damage assessments presented in technical documents. The macro-element method implemented in Tremuri was able to capture the structural behavior of the building, where slender piers suffer from bending damage and diagonal cracking appears for elements subjected to shear forces. Significant damages recorded for the masonry walls were also captured in the model by means of high damage percentages for macro-elements. The damages from the portico area observed after the 1977 earthquake were also present in the numerical model through large relative displacements of the structural elements.

The layout of openings on the façade, as well as the transition area between the two wings of the building favorized the accumulation of damage on certain areas and levels. Therefore, distinct analyses were done to evaluate the performance level function of relative displacements at global level and also at the wall's level. The ultimate drift recorded for the entire building indicated the exceedance of life safety performance level, while the relative damages from the portico overpass the collapse prevention drift limits.

A distinct model was done for the retrofitted version of the museum, based on the interventions performed in 1982. When comparing the results of the initial model with the retrofitted one, the lateral capacity increased up to $80 \%$ along the transversal direction, where most of the works were carried out, while the ultimate displacement was slightly reduced. Therefore, the overall seismic energy dissipation capacity reaches a $25 \%$ increase for the retrofitted model. On the other hand, significant reductions of relative displacements appear in case of the most vulnerable parts of the buildings, namely the portico and the façade walls, thus leading to a more uniform load distribution along structural walls on both directions. Taking into account that these types of invasive interventions are difficult to apply on heritage buildings due to architectural constraints, alternative retrofitting solutions should be considered for future interventions.

Acknowledgements. The authors would like to acknowledge the help of STAdata for providing an academic license of the Tremuri software.

\section{REFERENCES}

[1] Gospodinov, N. and Lozincă, E. Raport de expertiză tehnică privind starea structurii ansamblului imobiliar Muzeul Național de Geologie Sector 1, București (2011).

[2] Lagomarsino, S., Penna, A., Galasco, A. and Cattari, S. TREMURI program: An equivalent frame model for the nonlinear seismic analysis of masonry buildings. Eng.Struct. (2013) 56:1787-1799.

[3] Derakhshan, H. and Griffith, M. Final report on Pushover analysis of classes of URM building to characterize drift ratios for different damage levels. (2018).

[4] ASCE Prestandard and commentary for the seismic rehabilitation of buildings. FEMA 356 (2000).

[5] Cattari, S., Giongo, I., Marino, S. and Lin, Y. Numerical simulation of the seismic response of an earthquake damaged URM building. In: New Zeeland Society for Earthquake 
Engineering Technical Conference 2015 (2015).

[6] Fulop, L. and Sippola, M. Constructive and performance analysis of the retrofit systems for vertical masonry elements. Research report (2011).

[7] Hancilar, U., Durukal, E. and Erdik, M. Seismic assessment and rehabilitation of historical unreinforced masonry (URM) buildings in Istanbul. In: Improving the Seismic Performance of Existing Buildings and Other Structures (2009), pp. 1305-1316.

[8] Churilov, S. and Dumova-Javanoska, E. Analysis of masonry walls strengthened with RC jackets. In: 15 World Conference on Earthquake Engineering (2012) 